\title{
Comparison of antioxidant activity and flavanol content of cacao beans processed by modern and traditional Mesoamerican methods
}

\author{
Elizabeth Chin ${ }^{1}$, Kenneth B Miller ${ }^{3}$, Mark J Payne ${ }^{2}$, W Jeffery Hurst ${ }^{2 *}$ and David A Stuart ${ }^{2}$
}

\begin{abstract}
The use of cacao, in its familiar food and beverage form, dates back about 3,800 years. By the time of the discovery of America by Europeans, the Aztecs and Mayans had developed methods for drying, roasting and grinding cacao beans for use in beverages and foods. Today, the same processes are used, but have been adapted to modern machinery. The current study was conducted to compare the traditional Mesoamerican processing and modern processing methods and their impact on the antioxidant activity and flavan-3-ol content of the resulting processed cocoa mass. Two cocoa bean types were used: unfermented cocoa beans commonly produced and consumed today by the native peoples of Mesoamerica, and fermented Ivory Coast cocoa beans representing the most common country of origin for cocoa in the world today. Both bean types were processed by roasting and grinding using traditional and modern processing methods. The traditional method consisted of roasting whole beans on an earthenware comal heated with wood charcoal, de-shelling the beans, then grinding the beans to a paste using a stone metate and mano. The modern method consisted of roasting cocoa beans with pilot-scale equipment that simulates large-scale chocolate manufacturing using whole bean drum roasters, deshelling the beans followed by mechanical grinding using a ball mill producing a chocolate paste. The antioxidant capacity and flavanol content of these chocolate pastes were then determined. The data show that the antioxidant capacity and flavanol content of unprocessed Mexican Lavado cocoa beans were significantly higher than that of the unprocessed, fermented Ivory Coast cocoa beans. In unfermented Mexican Lavado cocoa beans, the traditional and modern processing revealed no clear advantage with respect to the antioxidant and flavanol contents. However, for fermented Ivory Coast beans, there were some differences in the level of flavanols between traditionally processed and modern processed fermented beans. These differences, while significant for some, but not all of the flavanol measures, were attributed to final roast temperatures achieved and to the possible lack of uniformity of bean fermentation.
\end{abstract}

Keywords: Theobroma cacao, Cacao, Cocoa, Processing, Flavanols, Antioxidants, Procyanidins, Mesoamerica

\section{Introduction}

Cacao originated and evolved in the tropical rainforests of the upper Amazon and Orinoco Rivers in South America [1]. When fresh fruit of cacao, also known as cocoa or cacao pods, are harvested, the hard woody pod is broken open and the cacao seeds, better known as cocoa beans, with their surrounding white, sweet pulp, are revealed. Fresh cacao beans at this stage taste bitter and contain little or no cacao flavor [2-4]. The archeological evidence dating

\footnotetext{
* Correspondence: whurst@hersheys.com

${ }^{2}$ The Hershey Center for Health and Nutrition, The Hershey Company, 1025 Reese Avenue, Hershey, PA 17033, USA

Full list of author information is available at the end of the article
}

back to about 1900 to $1400 \mathrm{BC}$, indicates that cacao juice expressed from the sweet pulp was the first product of the cacao seed to be used [5]. The archeological records suggest that the first consistent use of the brown, roasted cacao paste that was made into cocoa drinks, sauces and solid cocoa-containing foods dates back to about 1,000 BC [6]. The forms of cocoa that we are familiar with today have these brown cocoa solids - chocolate liquor and cocoa powder-which are the ingredients of chocolate candy, cakes, cookies and hot cocoa beverages.

While no one really knows how the processing of cocoa beans by fermentation, roasting and grinding actually developed, Edgar [7] speculates that Mayans routinely 
fermented cocoa beans for one to two days with their pulp to produce alcohol. He then speculates that if the Mayans separated the juice and dried the beans, the beans could be subsequently roasted on a comal found in most kitchens used to cook maize tortillas and stews (Figure 1) to produce cocoa aroma and beans with less bitterness. Indeed modern science has learned that fermentation lowers the bitterness of roasted cocoa beans as well as their content of flavan-3-ols $[8,9]$ while also creating more chocolate flavor when the beans are roasted [4]. Roasting also makes the inedible shells brittle and easy to remove. To make chocolate paste, Edgar speculates that roasted beans were ground using a kitchen grinding stone called a metate and a stone mano (Figure 2) which were also commonly available in households to make maize flour. We refer to this as the Traditional Process. These same processes of roasting, shell removal and milling have been mechanized and we refer to this as the Modern Process.

Cacao is known to contain very high levels of flavan3-ols (flavanols) that occur both as monomers of epicatechin and catechin and as polymerized flavanols, or procyanidins [9-13]. The flavanols are commonly associated with cardiovascular health benefits which include lower rates of morbidity and mortality due to stroke and heart attack, improved vascular endothelial function, reduction in blood pressure and increases in HDL cholesterol $[14,15]$.

Studies have shown that flavanols are lost during transformation of cocoa beans into chocolate. Therefore, one can ask the compelling question regarding the level of these flavanols: Do traditional processing methods for roasting cacao beans have an advantage over the modern methods used today to produce roasted cocoa beans for making chocolate, perhaps because the process is more natural or not mechanized? The objective of this study is to compare the level of antioxidant capacity, flavanol monomers as well as oligomers and total flavanols in cacao beans processed by traditional Mesoamerican methods to the levels found in cocoa beans processed by modern methods. Here we have studied two types of cacao beans: unfermented cacao beans from southern Mexico, locally known as Lavado beans (lavar, in Spanish, meaning to wash) and conventionally fermented Ivory Coast beans.

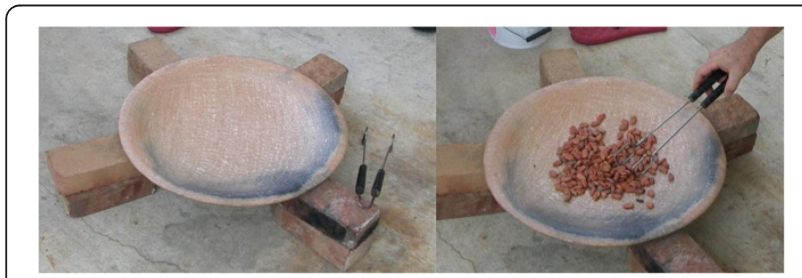

Figure 1 Traditional bean roasting. Comal (Left) with bricks to elevate it above charcoal heat from beneath. Bean roasting (Right) in which $250 \mathrm{gm}$ of Lavado beans are being prepared.

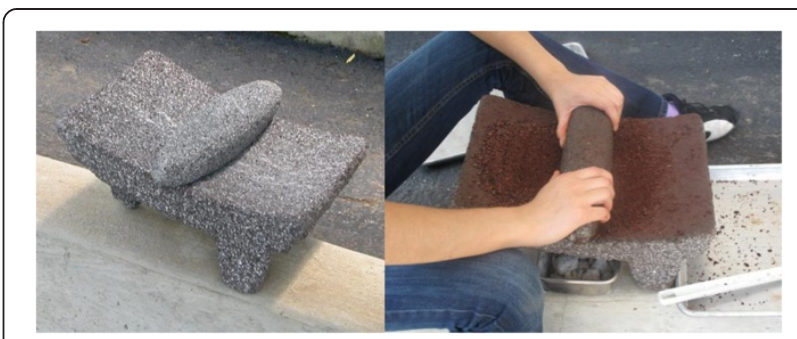

Figure 2 Traditional bean grinding. The metate base with the mano pestle on its surface (left). Bean grinding (right) on the metate. Note the charcoal heat being applied from beneath of the metate.

Beans of each type then were processed in a modern pilot plant to simulate industrial processing and were compared to beans prepared by the traditional Mesoamerican method which included comal roasting, hand winnowing and stone grinding on a metate.

\section{Material and methods}

\section{Cocoa bean samples}

Two types of cocoa beans were obtained for this study: Mexican unfermented Lavado and Ivory Coast fermented. The Mexican Lavado beans were obtained from AMCO (Veracruz, Mexico) and were processed according to the local Lavado tradition in the Chiapas, Mexico region. The beans were removed from ripe pods, washed by hand with water to remove most of the pulp, then sun-dried. This results in unfermented, terracotta colored beans which are typical from this region of Mexico (Figure 3). Ivory Coast beans were obtained as standard fair average quality beans through The Hershey Company's purchasing department. These beans typically are heap-fermented for four to six days and then sun-dried. Ivorian beans have the typical brown appearance of fermented beans (Figure 3, bottom,

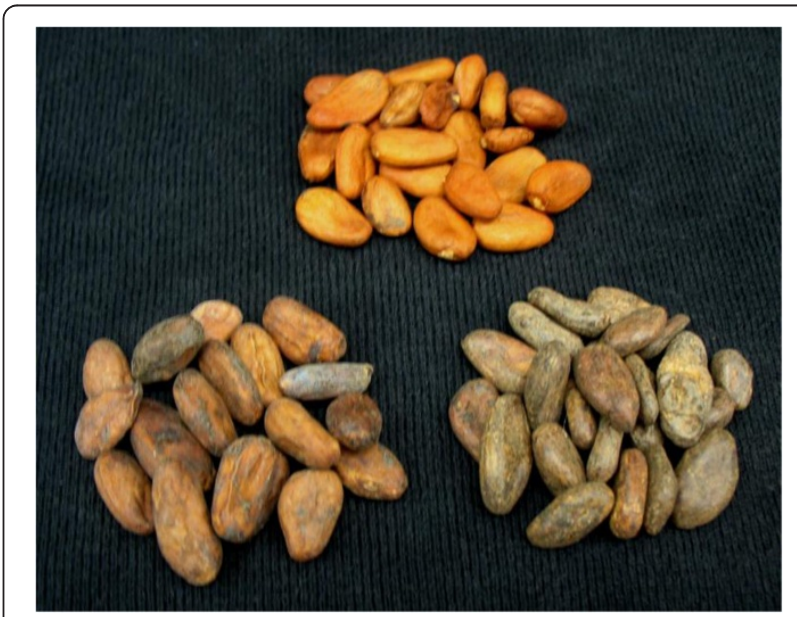

Figure 3 Unfermented and fermented cocoa beans. Mexican Lavado beans (Top, center) with their characteristic terracotta color. In the foreground are Ivory Coast fermented beans (Left; light brown) and Jamaica fermented beans (Right; dark brown). 
right). The dried Lavado and the Ivorian beans had a moisture content of between $5.5 \%$ to $6.5 \%$ and fat content of $51 \%$ to $52 \%$.

\section{Traditional processing method}

Cocoa beans were roasted using methods that resembled traditional, ancient processing and typical of those still used today in Central America for local use. A $50-\mathrm{cm}$ diameter earthenware comal was obtained from a Mexican market and was supported by several bricks. The comal was heated from beneath with charcoal (Figure 1). Once the center of the comal reached 250$300^{\circ} \mathrm{C}$ surface temperature as measured with a RayTek Mini-Temp Model MT6 laser thermometer (Fisher Scientific), $250 \mathrm{~g}$ of whole, dried cocoa beans were placed on the comal and heated. The beans were stirred occasionally with a spatula to avoid burning the outer shell. When beans developed a characteristic cacao aroma, they were heated for another three to four minutes, removed from the comal and cooled. Final external bean temperatures were $125-130^{\circ} \mathrm{C}$ as measured by a RayTek laser thermometer. The shells of roasted beans were fractured into small pieces using a stone mano and removed by hand or winnowed by sifting and blowing away the lighter shells from the heavier cocoa nibs. Shell-free nibs were ground using a stone metate and mano purchased from Melissa Guerra Cookware (Figure 2; bottom). The metate was kept slightly warm by charcoal underneath. The nibs were ground several times to produce a smooth, melted paste with a glossy appearance. Several batches were processed, combined and three aliquots were taken for analysis.

\section{Modern processing method}

Modern industrial roasting was accomplished on a pilot plant scale using $1362 \mathrm{~g}$ of whole, dried cocoa beans in a drum-style US Roaster. Burner temperature was set at $150^{\circ} \mathrm{C}$ and $2 \%$ water was added at the beginning of the roast. The beans were roasted to a final moisture content of less than $1 \%$ with a bean temperature of about $155^{\circ} \mathrm{C}$. Shell-free nibs were obtained using a bench-top BLT cracker and winnower. Nibs were made into liquor with a bench-top Netsch Ball Mill and ground to a $25 \mu \mathrm{m}$ particle size. Several batches were processed, combined, and three aliquots were taken for analysis.

\section{Sample preparation}

Composite samples from each type of roasting were analyzed, to avoid measuring batch to batch variability but rather focusing on the impact of the different processing methods. In all cases, unroasted and roasted cocoa beans by both traditional and modern processing methods had their shells removed and were ground to a consistent particle size. Prior to analysis for the three flavanol tests described below, the ground mass was defatted by extracting three times with hexane [16]. Final results are reported on per gram of original cocoa bean material.

\section{Antioxidant capacity measurement}

Total antioxidant activity of unroasted and roasted cocoa bean samples was measured by the ORAC assay. ORAC is a widely used fluorescent method for assessing antioxidant capacity in food and biological samples. It is based on the inhibition of a peroxy radical induced oxidation initiated by the thermally based decomposition of 2 , 2'- azobis- 2- methyl- propanimidamide, using fluorescein as a fluorescent probe and Trolox as a standard substrate. The results are expressed as $\mu$ mol Trolox equivalent (TE) per gram $[17,18]$.

\section{Flavanol monomer determination}

The flavanol monomers $( \pm)$-catechin and $( \pm)$-epicatechin were measured by the HPLC method of Nelson and Sharpless [19] standardized with (+)-catechin hydrate and (-)-epicatechin using the method recently validated using a five-laboratory ring test [20]. We define and report measures of $( \pm)$-epicatechin as epicatechin and $( \pm)$-catechin as catechin.

\section{Flavanol monomer to decamer determination}

The flavanol oligomers with degree of polymerization (DP) ranging from DP 1 to 10 were measured by the HPLC method of Robbins et al. [21] with each sample extract standardized using individual purified oligomeric standards isolated and characterized as described by Hurst et al. [22]. These standards were obtained from Planta Analytica (Danbury, CT). The data are reported as Flavanols DP 1-10.

\section{Total flavanol determination}

Total flavanols were measured by the DMAC method which has been validated by a three laboratory ring-test described by Payne et al. [23]. This method is based on the specific reaction of $p$-dimethylaminocinnamaldehyde with the flavanol structure. The test was standardized using procyanidin B2 purchased from Planta Analytica (Danbury, CT). The method is specific to monomeric and polymeric flavan-3-ols as well as to related compounds such as epigallocatechin gallate and epicatechin3-gallate. Monomers, i.e., epicatechin and catechin, react more strongly than higher MW oligomers with DMAC. Thus $\mathrm{mg} / \mathrm{g}$ may not change, but the various proportions of monomers to DP2 and higher may be altered with processing. These results are reported as Total Flavanols.

\section{Statistical analysis}

The data presented in this paper represent analysis of three representative samples for each sample type. Values for 
antioxidant activity and flavanol contents are expressed as averages and standard deviations. Due to the small sample populations, $\mathrm{p}$-values were calculated on the basis of a significant difference. Therefore, at a 95\% confidence level, p-values $\leq 0.05$ represent a significant difference between two sets of data.

\section{Results and discussion}

\section{Comparison of unprocessed Lavado and Ivorian beans}

Table 1 provides the antioxidant and flavanol content for the unroasted Lavado and Ivory Coast cocoa bean material. The current results agree with previously published literature [9-13], namely that less fermented Lavado nibs have higher ORAC values and more flavanol content than fermented Ivory Coast nibs as measured by flavanol monomers, flavanol DP $1-10$ and by total flavanols. As the literature has shown, ancient cultures would most likely have used less-fermented, Lavado-like cocoa beans. In fact, today there are areas ranging from southern Mexico to Venezuela where Lavado beans are preferred for local use. The reason is that beans washed free of the surrounding pulp are more easily dried during the rainy season and less subject to spoilage. However, today, chocolate manufacturers in the developed world rely on fermented beans like those from the Ivory Coast, because fermentation creates more chocolate flavor upon roasting and reduces the bitterness [3,4].

Since the focus of this study was a comparison of processing methods, the data presented in the following tables and graphs compare only the impact of traditional and modern bean processing on various antioxidant and flavanol measurements. A comparison will not be made to the unroasted starting material because the difference in moisture contents would create an unfair comparison.

\section{Processing of Lavado (unfermented) beans}

The data in Table 2 and Figure 4 shows a comparison of the antioxidant capacity and flavanol content of Lavado beans roasted by the traditional and modern methods. The major and perhaps surprising observation is that there were no significant differences in antioxidant capacity, epicatechin, flavanols DP $1-10$ and total flavanols. The catechin content of the modern processed beans, however, was significantly higher than traditionally processed beans. The results in Table 2 and Figure 4 are perhaps surprising since it has been found that increased roast temperatures can decrease flavanol content when temperatures in excess of $70^{\circ} \mathrm{C}$ are reached [13]. Since the modern processed beans reached a higher terminal temperature of $150^{\circ} \mathrm{C}$ compared to the $125^{\circ} \mathrm{C}$ to $130^{\circ} \mathrm{C}$ exterior temperature of the traditionally processed beans, we might have expected to see lower antioxidant activities and flavanol values in the modern processed Lavado beans, but this was not observed.

Our results with unfermented beans are different from those of Cervelotti et al. in 2008 [24] who comparing the in vitro antioxidant activity and polyphenol content of finished chocolates made for standard, large scale manufactured products and for artisan manufacturing methods which used small batch roasting and stone, melangeur grinding. They concluded that artisan-made chocolate had higher antioxidant capacities when compared to mass produced chocolate as measured by Briggs-Rauscher reaction and by the Trolox Equivalent Antioxidant Capacity (TEAC) methods. They also found higher levels of polyphenols in the artisan chocolates. But their study made no attempt to measure the flavan3-ol content of the chocolates, nor were they able to measure the antioxidant activities or the total polyphenol composition of the starting materials, as we have. Additionally, the Cervelotti study did not attempt to measure differences in their starting materials, nor differences in the processing methods used, since all of the chocolates produced would have used similar, but not identical, modern roasting and grinding techniques; the differences mainly being the scale of the manufacture. Our results with unfermented beans clearly show that there is a loss in antioxidant activity and flavanol content due to roasting but that there is no significant difference between the traditional process and the modern process in making chocolate mass.

\section{Processing of Ivorian (fermented) beans}

In Table 3 and in Figure 5 are presented the effects of traditional and modern processing on the flavanol content of fermented Ivory Coast beans. Ivory Coast in $2009 / 10$ represented the single largest origin of cocoa in the world producing 1.242 tones of cocoa or $34.1 \%$ of total world production [25]. The observations here are similar to the unfermented bean study. ORAC, epicatechin, and flavanols DP 1-10 were significantly higher in traditional processed beans by $20 \%(p=0.0021), 26 \%(p=0.0075)$, and

Table 1 Antioxidant capacity (ORAC) and flavanol content comparison for unroasted, unfermented Lavado beans and unroasted fermented Ivory Coast beans used in this study

\begin{tabular}{|c|c|c|c|c|c|}
\hline Bean type & $\begin{array}{c}\text { ORAC } \\
(\mu \mathrm{mol} \mathrm{TE} / \mathrm{g})\end{array}$ & $\begin{array}{c} \pm- \text { epicatechin } \\
\text { (mg/g) }\end{array}$ & $\begin{array}{c} \pm- \text { catechin } \\
(\mathrm{mg} / \mathrm{g})\end{array}$ & $\begin{array}{c}\text { Flavanols DP } 1-10 \\
(\mathrm{mg} / \mathrm{g})\end{array}$ & $\begin{array}{c}\text { Total flavanols } \\
(\mathrm{mg} / \mathrm{g})\end{array}$ \\
\hline Washed, Unfermented Lavado & $737 \pm 32$ & $6.53 \pm 0.25$ & $0.17 \pm 0.02$ & $37.18 \pm 0.38$ & $38.67 \pm 1.15$ \\
\hline Fermented Ivory Coast & $420 \pm 44$ & $1.53 \pm 0.06$ & $0.09 \pm 0.00$ & $10.18 \pm 0.09$ & $14.33 \pm 0.58$ \\
\hline
\end{tabular}

Three composite samples of each bean type were analyzed and values are expressed as average and standard deviation. 
Table 2 Antioxidant capacity and flavanol content comparison for unfermented Lavado cocoa beans roasted on a Mayan-style comal and ground on a metate (Traditional process) compared to the same beans roasted and ground using modern pilot plant equipment (Modern process)

\begin{tabular}{lccc}
\hline Measure & $\begin{array}{c}\text { Lavado beans, } \\
\text { traditional process }\end{array}$ & $\begin{array}{c}\text { Lavado beans, } \\
\text { modern process }\end{array}$ & p-value * \\
\hline ORAC $(\mu \mathrm{mol} \mathrm{TE} / \mathrm{g})$ & $620 \pm 17$ & $613 \pm 15$ & 0.6433 \\
\hline \pm- epicatechin $(\mathrm{mg} / \mathrm{g})$ & $3.57 \pm 0.15$ & $3.73 \pm 0.06$ & 0.1518 \\
\hline \pm- catechin $(\mathrm{mg} / \mathrm{g})$ & $1.77 \pm 0.15$ & $2.53 \pm 0.06$ & 0.0012 \\
\hline $\begin{array}{l}\text { flavanols DP 1-10 } \\
\text { (mg/g) }\end{array}$ & $18.12 \pm 0.72$ & $18.90 \pm 0.40$ & 0.6143 \\
\hline total flavanols $(\mathrm{mg} / \mathrm{g})$ & $36.00 \pm 1.00$ & $38.67 \pm 1.53$ & 0.0647 \\
\hline
\end{tabular}

*The $p$-values calculated on basis of a $95 \%$ confidence of a significant difference at $p \leq 0.05$.

Three composite samples were analyzed and values expressed as average and standard deviation.

$22 \%(p=0.0014)$ respectively. Conversely, catechin and total flavanols trended higher in modern processed beans by $14 \%(p=0.060)$ and $8 \%(\mathrm{p}=0.089)$ respectively, compared to traditionally processed beans. There are two possible explanations for these results. First, cocoa bean fermentations are done by very crude methods and the resulting fermented beans are highly heterogeneous with respect to degree of fermentation. This may impact the level of starting antioxidant capacity and flavanols in each bean. Therefore, one might expect more variability in the data from fermented beans compared to data from unfermented beans. Second, the higher terminal temperature in the modern processed beans partially, but does not fully, explain the selective loss of only antioxidant activity, epicatechin and flavanols DP 1-10 compared to the traditional process. But this does not explain why catechin and total flavanols are numerically higher (not significant at $p=0.05$ ) when processed by the modern method. If roasting had been done to the same final temperature, it is likely that any differences might disappear [13]. Since these observations do not show a clear trend towards modern or traditional processing, it can be concluded that there is little difference in the in vitro antioxidant activity and flavanol contents of the more fermented Ivory Coast beans when processed in the traditional or modern way. This brings us to the same general conclusion that the traditional and the modern processes for roasting and grinding cocoa beans have about the same effect on the level of cocoa bean flavanols.

When the Lavado bean processing data (Table 2) are compared to Ivory Coast processing data (Table 3), the same observation can be made that the antioxidant capacity and flavanol contents of roasted, unfermented Lavado beans are significantly higher than in the roasted, morefermented Ivory Coast beans (Table 1). This also is consistent with data published by Payne, et al. [13] and others

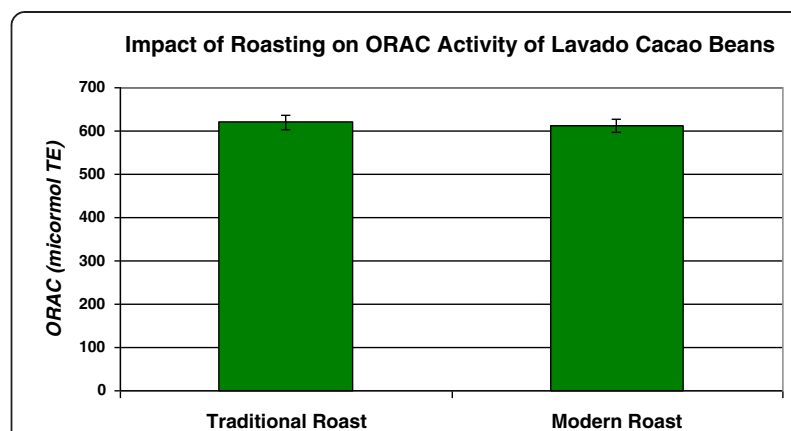

Impact of Roasting on Flavanol Monomers of Lavado Cacao Beans

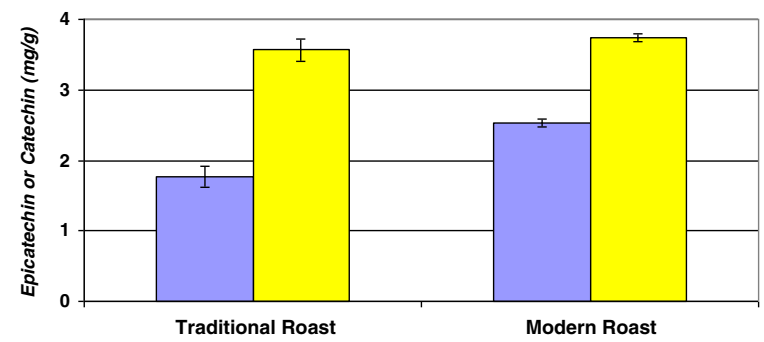

Impact of Roasting on Flavanols DP 1 to 10 of Lavado Cacao Beans

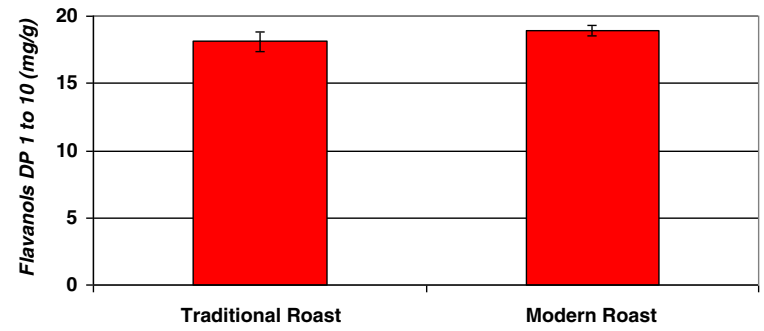

Impact of Roasting on Total Flavanols of Lavado Cacao Beans

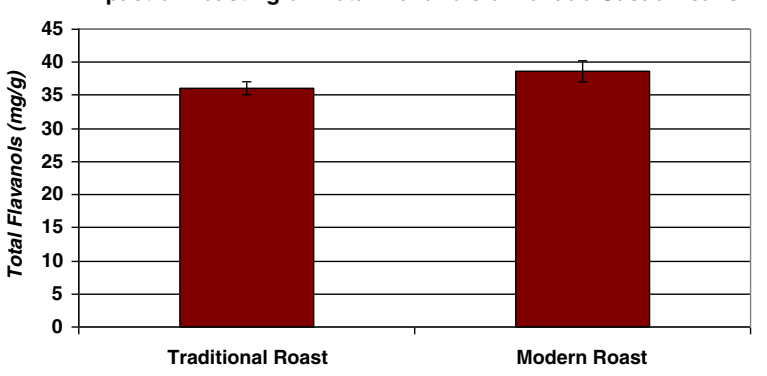

Figure 4 Comparison of unfermented (Lavado) cacao beans that have been left unprocessed, have been roasted and ground using traditional methods (Traditional Process) and have been processed using modern processing. Top Graph. Analysis of antioxidant activity (ORAC); Second Graph. Analysis of epicatechin (yellow bars) and catechin (blue bars) content; Third Graph, Analysis of Flavanols DP 1-10 content and Bottom Graph, Analysis of Total Flavanol content.

[10-12] where the flavanol monomer and oligomer content of roasted Lavado beans has been found to be significantly higher than roasted beans from fermented sources like Ivory Coast and Papua New Guinea. 
Table 3 Antioxidant capacity, and flavanol content comparison for Ivory Coast beans roasted on a Mayanstyle comal and ground on a metate (Traditional process) compared to the same beans roasted and ground using modern pilot plant equipment (Modern process)

\begin{tabular}{lccc}
\hline Measure & $\begin{array}{c}\text { Ivorian beans, } \\
\text { traditional process }\end{array}$ & $\begin{array}{c}\text { Ivorian beans, } \\
\text { modern process }\end{array}$ & $\begin{array}{c}\text { p-value } \\
\text { (if different) }\end{array}$ \\
\hline ORAC $(\mu \mathrm{mol} \mathrm{TE} / \mathrm{g})$ & $383 \pm 6$ & $317 \pm 15$ & 0.0021 \\
\hline $\begin{array}{l} \pm- \text { epicatechin } \\
\text { (mg/g) }\end{array}$ & $1.60 \pm 0.14$ & $1.27 \pm 0.06$ & 0.0075 \\
\hline $\begin{array}{l} \pm- \text { catechin } \\
\text { (mg/g) }\end{array}$ & $0.54 \pm 0.03$ & $0.63 \pm 0.05$ & 0.0596 \\
\hline $\begin{array}{l}\text { flavanols DP 1-10 } \\
\text { (mg/g) }\end{array}$ & $8.30 \pm 0.20$ & $6.79 \pm 0.30$ & 0.0014 \\
\hline $\begin{array}{l}\text { total flavanols } \\
\text { (mg/g) }\end{array}$ & $17.67 \pm 0.58$ & $19.33 \pm 1.15$ & 0.0890 \\
\hline
\end{tabular}

*The $p$-values calculated on basis of a $95 \%$ confidence of a significant difference at $p \leq 0.05$.

Three composite samples were analyzed and values expressed as average and standard deviation.

\section{Implications for traditional processing and modern processing}

People native to Mesoamerica and Northern South America have a tradition of consuming less-fermented or totally unfermented cocoa. This is due to the ease of processing and drying cocoa beans in humid climates, particularly during the rainy season, when the beans need to be quickly dried. Over the centuries these people have come to prefer the unfermented, Lavado beans. Regardless of the processing methods used, Lavado beans had the same level of flavanols and these levels were more than twice the level found in fermented beans after similar processing (compare Table 2 to Table 3). This may mean that people native to the Americas today and before the discovery of the New World by Columbus and Cortez, ate cocoa products made from cocoa mass (also called chocolate liquor) that contained about twice the level of flavanols found in today's cocoa mass.

After Europeans began importing cocoa beans, first for use in beverages, and then for solid chocolate, hot cocoa beverages and later milk chocolate, there was increased demand for partially or fully fermented cocoa beans. The producers of cocoa in the Americas were asked to produce cocoa beans that had been fermented to suit European tastes and were paid a premium for these beans $[3,4]$. As is shown in this study (Table 1), and by others [9-13], fermentation lowers the level of flavanols in the raw beans. The benefit to the European consumer was to have cocoa drinks or chocolate bars that were less bitter and had more cacao flavor. With the increased use of fermented beans and with the development of modern cocoa bean processing, there was a loss of flavanols from product, with the greatest loss of flavanols due to the preference for fermented beans. The results of the present study have shown that modern

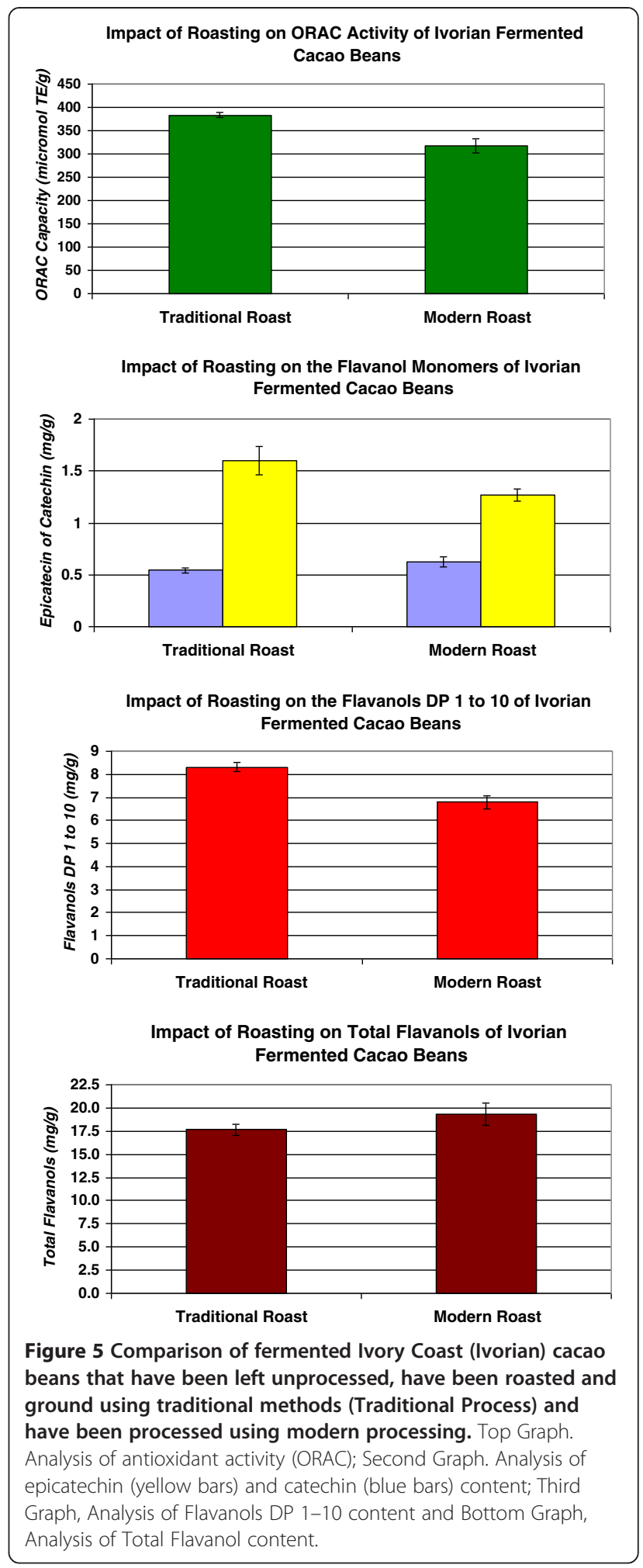

processing has little or no impact on flavanols (Table 3, Figure 5). Thus the health benefits of cocoa and chocolate flavanols and other beneficial bioactives need to be balanced with the flavor of the final product, for which 
fermentation of cocoa beans tends to increase cacao flavor impact and lessen bitterness. Despite the implementation of fermentation, dark chocolate and cocoa powder still have some of the highest concentrations of flavanols of any food in our diet [26]. In fact a recent dose response study using conventionally processed cocoa powder in ever increasing amounts has found that as little as $5 \mathrm{~g}$ is sufficient to elicit significant vasodilation of the brachial artery, as measured by Flow Mediated Dilation [27].

\section{Competing interests}

The authors declare that they have no competing interests.

\section{Authors' contributions}

EC, KM and DS carried out cocoa roasting while MP performed and directed the analysis of samples. WH assisted in experiment design, sample processing and directed the project. All authors read and approved the final manuscript.

\section{Acknowledgements}

The authors would like to thank the Hershey Center for Health and Nutrition for providing the samples and facilities for this research. We thank The Hershey Company for supplying support to E. Chin as part of her undergraduate summer internship. Thanks go to John Scharffenberger for his expert advice and direction for the ancient, traditional processing of cacao beans. Also, a special thanks to W. J. Hurst for the acquisition of an authentic clay comal from Latin America.

\section{Author details}

${ }^{1}$ Current address: Department of Food Science and Technology, University of California-Davis, Davis, CA 95616, USA. ${ }^{2}$ The Hershey Center for Health and Nutrition, The Hershey Company, 1025 Reese Avenue, Hershey, PA 17033, USA. ${ }^{3} 1025$ King Street, Palmyra, PA 17078, USA.

Received: 4 February 2013 Accepted: 18 March 2013

Published: 5 April 2013

\section{References}

1. Powis, et al: Cacao and the San Lorenzo Olmec. Proc Natl Acad Sci 2011, 108:8595-8600.

2. Coe SD, Coe MD: The True History of Chocolate. London, England: Thames and Hudson Ltd.; 1996.

3. Minifie BW: Chocolate, Cocoa and Confectionery. Westport, CT, USA: AVI Publishing Company; 1980

4. Beckett ST: Industrial Chocolate Manufacture and Use. Blackie: Glasgow and London; 1988:388.

5. Henderson JS, Joyce RA, Hall GR, Hurst WJ, McGovern PE: Chemical and archaeological evidence for the earliest cacao beverages. Proc Natl Acad Sci USA 2007, 104:18937-18940.

6. Hurst WJ, Tarka SM Jr, Powis TG, Valdez F Jr, Hester TR: Cacao usage by the earliest Maya civilization. Nature 2002, 418:289-290.

7. Edgar B: The power of chocolate: tracking the chemical signature of cacao across Mesoamerica. Archaeology 2010, 63. Nov/Dec., 20-25.

8. Thompson SS, Miller KB, Lopez AS: Chapter 39, Cocoa and Coffee. In Food Microbiology: Fundamentals and Frontiers, 3rd Ed. Washington DC: ASM Press; 2007.

9. Harborne JB, Baxter H, Moss GP: Phytochemical Dictionary: a handbook of bioactive compounds from plants. 2nd edition. London, United Kingdom: Taylor and Francis; 1999.

10. Kim H, Keeney PG: (-)-Epicatechin content in fermented and unfermented cocoa beans. J Food Sci 1984, 49:1090-1092

11. Porter $\sqcup, M a$ Z, Chen BC: Cocoa procyanidins: Major flavonoids and identification of some minor metabolites. Phytochemistry 1991, 20:1657-1663.

12. Lea PJ, Ford GD: Characterization of the polyphenols of cocoa. Glasgow: BioFlavors Conference; 1990.

13. Payne MJ, Hurst WJ, Miller K, Rank C, Stuart DA: Impact of fermentation, drying, roasting, and Dutch processing on epicatechin and catechin content of cacao beans and cocoa ingredients. J Ag Food Chem 2010, 58:10518-10527.
14. Hooper L, Kay C, Abdelhamid A, Kroon PA, Cohn JS, Rimm EB, Cassidy A: Effects of chocolate, cocoa and flavan-3-ols on cardiovascular health: a systematic review and meta-analysis of randomized trials. Am J Clin Nutr 2012, 95:740-751.

15. Reid K, Fakler TR, Frank OR, Stocks NP: Effect of cocoa on Blood Pressure (Review). The Cochrane Collaboration. John Wiley Press; 2012:1-83.

16. Association of Analytical Chemists, International: Cacao mass (fat-free) of chocolate liquor. Official Methods of the AOAC International, 16th Ed. AOAC Official Method. Gaithersburg, MD: AOAC International; 1995. 931.05.

17. Ou B, Hampsch-Woodill M, Prior R: Development and validation of an improved oxygen radical absorbance capacity assay using fluorescein as the fluorescent probe. J Agric Food Chem 2001, 49:4619-4626.

18. Huang D, Ou B, Hampsch-Woodill M, Flanagan J, Deemer EK: Development and validation of oxygen radical absorbance capacity assay for lipophilic antioxidants using randomly methylated-cyclodextrin as a solubility enhancer. J Agric Food Chem 2002, 50:1815-1821.

19. Nelson BC, Sharpless KE: Quantification of the predominant monomeric catechins in baking chocolate standard reference material by LC/APCI-MS. J Agric Food Chem 2003, 51:531-537.

20. Shumow L, Bodor A: An industry consensus study on an HPLC fluorescence method for the determination of $( \pm)$-catechin and $( \pm)$-epicatechin in cocoa and chocolate products. Chemistry Central Journal 2011, 5(39):MS ID: 7184481134944588

21. Robbins RJ, Leonczak J, Johnson JC, Li J, Kwik-Uribe C, Prior RL, Gu L: Method performance and multi-laboratory assessment of a normal phase high pressure liquid chromatography-fluorescence detection method for the quantitation of flavanols and procyanidins in cocoa and chocolate containing samples. J Chromatorgr A 2009, 1216:4831-4840.

22. Hurst WJ, Stanley B, Glinski JA, Davey M, Payne MJ, Stuart DA: Characterization of primary standards for use in the HPLC analysis of the procyanidin content of cocoa and chocolate containing products. Molecules 2009, 14:4136-4146.

23. Payne MJ, Hurst WJ, Stuart DA, Ou B, Fan E, Ji H, Kou Y: The use of the DMAC assay for determination of total procyanidins in selected chocolate and confectionery products. J AOAC International 2010, 93:89-96.

24. Cervelatti R, Greco E, Costa S, Guerra M, Speroni E: A comparison of antioxidant properties between artisan-made and factory-produced chocolate. International Journal of Food Science \& Technology 2008, 43:1866-1870.

25. ICCO statistics for World Cocoa Production. 2009. http://www.icco.org/ statistics/production-and-grindings/production.html.

26. USDA Database for the Proanthocyanidin Content of Selected Foods. 2004 http://www.nal.usda.gov/fnic/foodcomp/Data/PA/PA.html

27. Monahan KD, Feehan RP, Kunselman AR, Preston AG, Miller DL, Lott MEJ: Dose dependent increases in flow-mediated dilation following acute cocoa ingestion in healthy older adults. J Appl Physiol 2011, 111:1568-1574.

doi:10.1186/2050-7445-1-9

Cite this article as: Chin et al:: Comparison of antioxidant activity and flavanol content of cacao beans processed by modern and traditional Mesoamerican methods. Heritage Science 2013 1:9.

\section{Publish with ChemistryCentral and every scientist can read your work free of charge \\ "Open access provides opportunities to our colleagues in other parts of the globe, by allowing anyone to view the content free of charge." W. Jeffery Hurst, The Hershey Company. \\ - available free of charge to the entire scientific community \\ - peer reviewed and published immediately upon acceptance \\ - cited in PubMed and archived on PubMed Central \\ - yours - you keep the copyright \\ Submit your manuscript here: \\ http://www.chemistrycentral.com/manuscript/<smiles>c1ccccc1</smiles> \\ ChemistryCentral}

